\title{
Do folhetim à crônica: gêneros fronteiriços entre o livro e o jornal
}

Jeana Laura da Cunha Santos

\section{Resumo}

A autora se propõe trazer à tona um instante pioneiro de experimentação do corpo móvel e público do jornal através do folhetim e da crônica na virada do século XIX para o XX. Estas passagens elucidam algumas percepções novas no imaginário da época, subscritas aqui pelas experiências de fragmentação, movimentação, choque e coletivização do corpo cultural e social, refletidos na forma moderna e reprodutível do jornal.

Palauras-chave:

Folhetim, Crônica, Literatura, Jornalismo

\section{From feuilleton to chronicle: frontier genres between the book and the newspaper}

\section{Abstract}

The author proposes to bring up a pioneer instant of journal's mobile and public body experimentation through feuilleton and chronicle by the turning from 19th to 20th century. These crossings elucidate some new perceptions of that time imaginary, here subscribed by the experiences of fragmentation, movement, shock and collectivization of the social and cultural body, reflected in the modern and reproducible form of journal.

Key words:

Feullleton, Chronicle, Literature, Journalism

Sobre a autora

Doutora em Teoria Literária pela Universidade Federal de Santa

Catarina (UFSC), Professora da Faculdade Estácio de Sá de Santa Catarina jeanasantos@terra.com.br 


\section{Do livro ao jornal: o folhetim}

Ainda no começo do século XIX, a literatura permanecia viva dentro das primeiras formas de jornal, uma vez que os principais homens de letras é que eram os seus colaboradores. Se os países europeus passaram a substituir a prensa a vapor pela prensa tipográfica, e já no fim do século XVIII o jornal desmembravase cada vez mais do livro, no Brasil, a simbiose entre literatura e jornalismo se estenderia até o começo do século XX. Por esse tempo, o jornal ainda trazia em suas páginas inumeráveis artigos (os chamados artigos-de-fundo), cujas características eram a opinião, os narizes de cera, a extensão. Pouco havia de publicidade ou fotografia (via charge, fotogravura ou fotografia). Muito ainda havia de literatura (via conto, folhetim, poesia e crônica). Como se vê, o jornal retém a dialética de um tempo em que a escritura tornada mercadoria convivia lado a lado com a escritura sagrada do livro, cuja aura relutava em desaparecer.

Esse hibridismo encontraria no folhetim uma das primeiras formas de passagem entre o livro e o jornal. Gênero específico do Romantismo europeu, fora importado pelo Brasil, convertendo-se no melhor atrativo do jornal. Sucessos como os alcançados pelo Guarani, publicado entre fevereiro e abril de 1857, e A viuvinha, em 1860, ambos no Diário do Rio de Janeiro, revelam a popularidade do produto. Ler o folhetim virou hábito familiar, tanto na Corte quanto nos serões das províncias, e durante sua leitura oral era permitida a presença das mulheres e a participação dos analfabetos, que eram a maioria (Sodré, 1977: 279).

Autores nacionais se entregariam ao novo gênero, como Machado de Assis, com A mão e a luva em O Globo, em 1874, e com Iaiá Garcia em O Cruzeiro, em 1878. É a forma encontrada pelos autores de divulgarem o seu trabalho, uma vez que, na segunda metade do século XIX, a impressão de livros aqui no Brasil era uma raridade. Ou se os imprimia no exterior ou se tinha que contentar com produtos gráficos rudimentares, como os opúsculos (folhetos impressos que não chegavam a ser livro). Almanaques e folhinhas também iriam tentar suprir uma demanda por leitura que crescia gradualmente. Num contexto como esse, muitos literatos optariam por embarcar no veículo jornal, em que pesem as dificuldades enfrentadas também por esse último. E como nesta fase é o tom ameno que dá a tônica da imprensa, uma vez que o poder imperial estava no seu auge, predominando o latifúndio escravista e a estagnação política, o folhetim se converteria numa forma adequada ao momento. Como o público leitor do folhetim era formado, em sua maior parte, por moças casadouras e estudantes, os temas abordados eram o casamento e o amor, muito embora houvesse um enorme descompasso na importação de um ideário europeu num Brasil constituído pelo atraso.
O jornal retém a dialética de um tempo em que a escritura tornada mercadoria convivia lado a lado com a escritura sagrada do livro, cuja aura relutava em desaparecer 
Machado de Assis (In Coutinho, 1959: v.3) denunciaria este descompasso no conjunto de textos denominados "Aquarelas" (Espelho, 11 e 18 set. e 9, 16 e 30 out. 1859) onde argumenta que o folhetim, originário da França, dificilmente poderia se aclimatar entre nós. Comparando-o a uma planta em solo estrangeiro, especula que a incompatibilidade poderia ser defeito de suas propriedades orgânicas ou da diferença climática. Da França, teria se espalhado pelo mundo, sobretudo onde "o grande veículo do espírito humano" tomava maiores proporções. Tal veículo é o jornal. "O folhetim nasceu do jornal, o folhetinista por conseqüência do jornalista. Esta íntima afinidade é que desenha as saliências fisionômicas na moderna criação". Do primeiro, herdaria o fútil e o frívolo; do segundo, o útil e o sério. Depois de discorrer sobre as dificuldades de se escrever por encomenda (a abstração e a liberdade versus o cálculo e o dever) e de constatar que o folhetim é visto como um "confeito literário" sem horizontes vastos e, portanto, não recebedor de aplausos ou apoio do bom senso e da razão, o autor denuncia que a "cor local" raramente teria encontrado representação no folhetinista daqui: "Em geral, o folhetinista aqui é todo parisiense; torce-se a um estilo estranho, e esquece-se, nas suas divagações sobre o boulevard e café Tortoni, de que está sobre um mac-adam lamacento e com uma grossa tenda lírica no meio de um deserto". Sem deixar de constatar que "escrever folhetim e ficar brasileiro é na verdade difícil", Machado reivindica uma maior independência do espírito nacional, "tão preso a essas imitações, a esses arremedos, a esse suicídio de originalidade e iniciativa”.

Nota-se que as características que Machado dá ao folhetinista são mais apropriadas ao cronista, o que evidencia o quanto os gêneros ainda eram difusos aqui no Brasil, tendo em comum apenas o fato de não mais se sagrarem no livro, mas no "veículo do espírito moderno" chamado jornal. O próprio jornal, nascido no bojo de uma Europa que se queria liberal e moderna, não poderia se aclimatar totalmente num Brasil marcado pelo atraso industrial, pelo analfabetismo e pela escravidão.

Num contexto em que apogeu econômico se mistura com miséria, em que iluminismo se mescla ao obscurantismo e à barbárie, em que o desejo de ilustração sucumbe ao analfabetismo, o próprio surgimento do jornal - esse expoente de uma técnica moderna e cosmopolita - confrontar-se-ia com a dura realidade de uma massa iletrada e pobre. Não só o jornal seria vítima desse descompasso, mas a própria formação dos romances brasileiros se daria numa tênue linha entre o que era próprio e o que era alheio.

Foi baseado em contradições e impasses como esse que Schwarz arriscaria dizer que as idéias no Brasil, no que diz respeito à formação da literatura do século XIX, estariam "fora de lugar". Afirma ele que a literatura desse período refletiria o descompas-
As características que Machado dá ao folhetinista são mais apropriadas ao cronista, o que evidencia o quanto os gêneros ainda eram difusos aqui no Brasil, tendo em comum apenas 0 fato de não mais se sagrarem no livro 
so entre uma sociedade escravista, estagnada e baseada em relações de favor, e as idéias do liberalismo europeu, essas últimas formuladas com base em processos históricos distintos dos nossos, calcados em revoluções e na mobilidade social que as constituíam. Como dependíamos, além do trabalho escravo, do mercado externo, o autor considera natural a presença entre nós do raciocínio econômico burguês, mas, por outro lado, argumenta que esse conjunto ideológico iria inevitavelmente chocar-se com a escravidão. Neste contexto, a ideologia liberal só poderia soar postiça: "a ciência era fantasia e moral, o obscurantismo era realismo e responsabilidade, a técnica não era prática, o altruísmo implantava a mais-valia etc" (Schwarz, 1992: 15).

$\mathrm{O}$ mesmo descompasso pode ser dito com relação à consolidação da imprensa. Por mais que a vida urbana avançasse, que a classe média crescesse e que um esboço de burguesia se fizesse notar, havia ainda o país da estagnação política imperial, da escravidão e do latifúndio, instituições que só começariam a ser postas em xeque na imprensa com o surgimento de vários jornais republicanos a partir do final da década de 60 do século XIX.

Mas, juntamente como toda essa revolução nos aspectos da cidade, a capital experimenta também uma fase de especulação cambial, agiotagem e falso luxo, este último presente na imitação do estilo europeu das roupas, da música, das danças de salão, da mobília doméstica, do idioma e, também, da literatura (Sevcenko, 1983: 250). Afinal, com a implantação do novo ideário financeiro nascido com a República, era necessário também remodelar os hábitos nacionais, importando não só o comércio, mas qualquer produção cultural ou "novidade" provenientes do Velho Mundo. O personagem Mendonça, de Helena (1876), antes mesmo do novo Regime, ganha de Machado uma descrição que excede a sua fisionomia ou caráter, revelando a importância da moda parisiense no cenário local: "Vestia com o maior apuro, como verdadeiro parisiense que era, arrancado de fresco ao grand boulevard, ao café Tortoni e às récitas do Vaudeville. A mão larga e forte calçava fina luva cor de palha, e sobre o cabelo, penteado a capricho, pousava um chapéu de fábrica recente" (Coutinho, 1959: 44).

Além de os navios europeus, sobretudo os franceses, transportarem mobiliário, artigos de luxo e figurinos da moda, traziam também escolas filosóficas dominantes, modelos de comportamento, notícias sobre peças e livros em voga e modelos literários preponderantes.

O folhetim, quando veiculava uma atmosfera europeizante, seja pela importação do romance estrangeiro servido em fatias ou pela tentativa de imitá-lo por parte de nossos autores, contribuía para esse clima de "falso luxo", conferindo prestígio aos 
jornais e um sentimento de cosmopolitismo para quem os lia. $\mathrm{Na}$ verdade, as preferências da Corte carioca por produtos franceses de luxo e a imigração de comerciantes e artesãos franceses no fim do século XIX já vinham reforçando o gosto da elite carioca, que não se furtava também de passar longas temporadas em Paris. A educação dessa elite também era basicamente francesa e se revelava na aprendizagem da língua e no consumo da literatura: "Na verdade, vários literatos escreviam e alguns até pensavam naquela língua", argumenta Needell, para quem os setores médios, se não conheciam a cultura francesa tão bem, apreciavam suas realizações e o status a elas associado. Para ele, isso explica o fato de tantos literatos brasileiros traduzirem regularmente folhetins franceses nos jornais e a popularidade do drama francês traduzido (Needell, 1993: 230). Para Antonio Candido, a penúria cultural do nosso país teria levado muitos escritores a se voltarem para os padrões metropolitanos e europeus. Como não havia público local suficiente, esses escritores escreviam como se o seu público ideal estivesse na Europa, dissociando-se muitas vezes do Brasil. "Isto dava nascimento a obras que os autores e leitores consideravam altamente requintadas, porque assimilavam as formas e os valores da moda européia. Mas que, pela falta de pontos locais de referência, podiam não passar de exercícios de mera alienação cultural" (Candido, 1989: 148). Nesse sentido, a natureza do folhetim imprimiria um ar festivo e europeu a um país que mesclava atraso e afã por desenvolvimento, favor e liberdade individual.

Como se vê, tanto as idéias como o espírito que consolidaria o jornal no Brasil movem-se numa dupla face, identificada por Schwarz quando descreve a ambivalência ideológica das elites brasileiras: "Estas se queriam parte do Ocidente progressista e culto, naquela altura já francamente burguês (a norma), sem prejuízo de serem, na prática, e com igual autenticidade, membro beneficiário do último ou penúltimo grande sistema escravocrata do mesmo Ocidente (a infração)" (Schwarz, 1990: 41). Needell também argumenta que esses indivíduos queriam terminar com o Brasil antigo, "africano", que ameaçava suas pretensões à Civilização, mas ainda tinha a África muito próxima a eles, tanto em casa, ao viverem rodeados de empregados negros, quanto nas ruas, onde cerca da metade da população era composta de descendentes de africanos cujas tradições mesclavam-se à tentativa de afrancesamento dos costumes e do aspecto da cidade.

Assim, a sociedade brasileira, por mais que quisesse parecer européia (no século XIX, ser civilizado significava seguir a França e a Inglaterra), copiando o folhetim da França, ou quisesse parecer moderna, adotando a "literatura universal" do jornal, teria que inevitavelmente se confrontar com essas contradições. 
Não obstante, por mais que não pudéssemos ignorar essa peculiaridade da constituição da nossa identidade nacional, engendrada pelo papel do regime escravista numa civilização que se queria moderna e pelas relações de proteção e favor característicos do patriarcado rural, o fato é que havia um afã europeizante muito forte nos costumes brasileiros do período que se manifestava de várias formas (no urbanismo, nas modas, no comércio, no idioma, no comportamento etc.) e que forneciam os signos para a atmosfera de Civilização e para a distinção e superioridade da elite carioca. Adotando símbolos da aristocracia franco-inglesa tanto no comportamento quanto no consumo, essa elite pretendia forjar aquilo que Needell chamaria de "belle époque tropical". Não seria diferente com a forma literária, que teria que se modificar para circular naquele veículo mais apropriado aos tempos modernos: o jornal.

Portanto, se as idéias não estão exatamente no lugar no que se refere à importação do ideário burguês pelo Brasil, há sinais de uma tentativa de aproximar-se dele, em que pese o seu caráter postiço, falso, dentro de uma realidade tão desigual. Tal tentativa se faria presente nos costumes, no urbanismo, na língua, nas modas, na literatura e nas novas técnicas das quais o jornal é um produto sintomático, mediando uma nova forma de escrever dirigida agora para as ruas.

Entre o "mac-adam lamacento" e o "boulevard e café Tortoni", os literatos brasileiros abandonariam a casa da palavra para se dirigir à rua. A casa é o livro. A rua é o jornal. A passagem pelos dois territórios deu-se primeiro pelo folhetim e depois pela crônica.

\section{Do livro ao jornal: a crônica}

Com o romance-folhetim, o livro é seccionado para a produção em série do jornal. Mas enquanto o romance-folhetim tem ainda os olhos voltados para o interior burguês, a crônica já nasce no "olho" da rua e com os olhos voltados para a rua. Para as minimas histórias da rua, e sua forma revela essa perspectiva estilhaçada. O texto sofre fraturas, encurta-se, desmembra-se para caber nas páginas volantes e voláteis do jornal. Nesse contexto, os fragmentos de texto, as ruínas, adquirem importância fundamental. Borinski (1984: 200), citado por Benjamin em Origem do drama barroco alemão, declarou, a respeito da forma como os alegoristas barrocos reapropriavam-se das ruínas:

A fachada partida, as colunas despedaçadas, têm a função de proclamar o milagre de que o edifício em si tenha sobrevivido às forças elementares da destruição, do raio, e do terremoto. Em sua artificialidade, essas ruínas aparecem como último legado de uma Antigüidade que no solo moderno só pode ser vista, de fato, como um pitoresco monte de escombros. (Grifos nossos.) 
Quando o palácio do livro estilhaçou-se sob o olhar do espectador moderno, seus fragmentos produziram pequenas partículas volantes, histórias mínimas, uma tal de literatura menor que fora se alojar, sem dor nem pesar, na morada portátil do jornal. Seu nome: crônica. Vestígio, entulho, ruína daquilo que era heterônomo, incompleto, despedaçado, leve demais, para que o livro a quisesse, a crônica proclama a primazia do fragmentário sobre o total, das pequenas histórias sobre a História total.

Daí a predileção da crônica pelos mínimos, como bem o revelara Bilac em crônica da Gazeta de Notícias do dia 7 de fevereiro de 1904 (In Dimas, 1996: 19):

Os cronistas são como os bufarinheiros, que levam dentro das suas caixas rosários e alfinetes, fazendas e botões, sabonetes e sapatos, louças e agulhas, imagens de santos e baralhos de cartas, remédios para a alma e remédios para os calos, breves e pomadas, elixires e dedais.

É na estética da crônica que o pormenor esvaziado do sentido cotidiano, catado no chão das ruas da grande metrópole, ressurge aos olhos do observador como material poético ou histórico. A linguagem, pela via da crônica, fragmenta-se e vitriniza-se para passear feito flâneur pela cidade, recolhendo seus resíduos, suas ruínas, e devolvendo-os em forma de mercadoria.

Assim, entre a vacuidade do tempo descartável do jornal, a crônica torna-se resíduo, torna-se lixo. Mas, por um paradoxo, ao incorporar o estilhaçamento do tempo, tanto na forma quanto nos assuntos que cata no chão, é digna de se configurar como um monumento da história. Um monumento que se despedaça, já uma ruína, subscrita não na história linear, feita de uma sucessão de etapas num tempo homogêneo, mas a história antilinear, cuja base é a descontinuidade, a ruptura, a catástrofe, em suma, um acúmulo de ruínas.

A crônica como ruína mostra que a história nem sempre é feita só de medalhões e dandies, mas também de naturezas subalternas. Ou como disse Brás Cubas, aproximando-se da descrição de Borinski a respeito das ruínas que insistem em sobreviver, tal qual escombros, sob a destruição dos monumentos:

Quem não sabe que ao pé de cada bandeira grande, pública, ostensiva, há muitas vezes várias outras bandeiras modestamente particulares, que se hasteiam e flutuam à sombra daquela, e não poucas vezes lhe sobrevivem? Mal comparando, é como a arraia-miúda, que se acolhia à sombra do castelo feudal; caiu este e a arraia ficou (Assis, 1992: 23).
Vestígio, entulho, ruína daquilo que era heterônomo, incompleto, despedaçado, leve demais, para que o livro a quisesse, a crônica proclama a primazia do fragmentário sobre o total 
a uma só vez, ela parece penetrar agudamente na substância íntima de seu tempo e esquivar-se da corrosão dos anos, como se nela se pudesse sempre renovar, aos olhos de um leitor atual, um teor de verdade íntima, humana e histórica, impresso na massa passageira dos fatos esfarelando-se na direção do passado.

A crônica liga, assim, o passado (linhagens medievais) e o presente (registro do já); media a literatura canônica e a reportagem para as massas; transita entre o espaço doméstico, privado, e o movimento das ruas, público; fixa-se na fronteira limítrofe entre a mercadoria e a arte, entre o jornal e o livro. Pela sua inerente ambigüidade, documenta para sempre, à parte a transitoriedade que a habita, um tempo pioneiro em que a casa sagrada do livro esfarelou-se em partículas móveis, cujo campo de experiência não é mais o transcendente, mas a experiência viva e palpável da cidade. Ela se deixa preencher pelo próprio movimento do tempo e pelo veículo no qual viaja.

Marlyse Meyer (In Candido, 1992: 93-133), tentando traçar uma cronologia do gênero, ressalta o seu caráter difuso. Segundo ela, nos começos do século XIX, le feuilleton designava o rodapé da primeira página dos jornais, espaço destinado ao entretenimento e onde valia tudo: contar piadas, propor charadas, oferecer receitas... De espaço vale-tudo, passa, em finais de 1830, a publicar ficção em fatias, com enorme benefício financeiro para os jornais. Escritores como Eugène Sue, Alexandre Dumas, Ponson du Terrail, e outros, vão contar histórias sob medida para essa nova forma de ficção. Além, é claro, de praticamente todos os romances passarem antes pelo espaço do folhetim para depois se tornarem volumes.

Aqui no Brasil, a importância do gênero foi ressaltada por Justiniano José da Rocha, em 1836, quando lançou $O$ Chronista e, em 1838, tornou-se fundamental no Jornal do Comércio quando esse passou a importar da França os romances serializados que lá se publicavam e que garantiriam, também aqui, uma boa saúde financeira aos jornais. Mas é no corpo interno do Jornal do Comércio, sob a rubrica de Variedade, que, em fins de 1830, passa-se a publicar aquilo que viria a dar na crônica: conteúdos variados, matérias traduzidas, resenhas, ficções curtas, poesias, lista de traduções etc. O romance-folhetim, "avô de todas as nossas novelas", continuaria a ocupar o rodapé da página um. Em ambos os casos, folhetim-variedade ou romance-folhetim, alguns escritores, ao terem que traduzir ou escrever a toque de caixa pelo novo imperativo da velocidade do meio jornal, transpuseram esse modo de escrita para o seu posterior texto de ficção, o que comprova a simbiose estabelecida nesse momento de transição, via folhetim ou crônica, entre a literatura e o jornalismo.
Alguns escritores, ao terem que traduzir ou escrever a toque de caixa pelo novo imperativo da velocidade do meio jornal, transpuseram esse modo de escrita para o seu posterior texto de ficção 
Mas, se Marlyse Meyer coloca o surgimento do folhetim na França, Emy Armañanzas e Javier Diaz Noci o colocariam na Inglaterra. Segundo os autores, desde que Daniel Defoe publicou, em 1719, Robison Crusoé, no jornal Daily Post, dando origem ao primeiro folhetim da história da imprensa, o espaço literário e de opinião estavam garantidos nos jornais. O século XVIII inglês viu nascer uma corrente que perduraria até nossos dias: o ensaio. Mescla de opinião e informação, esse gênero era muito praticado pelo The Times (Armañanzas/Noci, 1996: 73-76).

Esse mesmo duo opinião/informação que também estaria presente na crônica. E a crônica, assim como todos aqueles outros textos que não eram de todo ficção, abrigar-se-iam sob a denominação folhetim. Assim, o gênero teria nascido no século XIX, ocupando a seção denominada folhetim, e abarcando desde o romance, o conto e a própria crônica, até a poesia e os comentários sobre o dia-a-dia da vida da cidade.

Depois de traçar todo o percurso do folhetim, Meyer fala dos "outros textos":

Cães vadios, livres farejadores do cotidiano, batizados com outro nome vale-tudo: a crônica. Cães sem dono, também, que são na maior parte anônimos ou assinados com iniciais. Envergonhados, quem sabe, de um escrito que não se enquadra propriamente num gênero, que é quase uma fala, coisa de casa, useira e vezeira, literatura de pé-dechinelo. O que não é pejorativo...

Adotando o tom ligeiro, miúdo, da fala cotidiana, a crônica passou a incorporar também um toque de humor, libertando-se, enfim, do folhetim e passando a ter vida própria, sendo esse um momento crucial para o seu amadurecimento. Foram raros os escritores da época, conforme Freyre (1974: 249),

que não se fizeram notar pela sua presença nos jornais ou nas revistas; que ao gôsto ou empenho pela criação artística ou literária, não juntassem o desejo de influir na vida nacional; de atuar sôbre o público; de participar da política; de intervir na discussão dos problemas do dia. Davam quase todos os escritores a essa intervenção um aspecto que não sendo o puramente literário, não se tornava nunca o apenas jornalístico.

$\mathrm{Na}$ verdade, o aumento do ingresso dos literatos no jornalismo é também resultado das oscilações sociais e econômicas geradas no final do Império e inícios da República, o que acabava impedindo o desenvolvimento amplo do mercado editorial. Como já não havia mais uma aristocracia tão disposta a assegurar a sobrevivência dos intelectuais, esses viram-se compulsoriamente 
arrastados para o jornalismo, o funcionalismo ou a política (Sevcenko, 1983: 101). Os livros de autores brasileiros eram poucos e baixas eram as tiragens. Assim, a reputação do autor passou a ser cada vez mais determinada pelos periódicos, cujos consumidores eram ainda as mulheres da elite e dos setores médios que imitavam a elite, estudantes, literatos ou aspirantes a literatos com um gosto francófilo e que mudava de acordo com a moda.

A migração dos escritores para os jornais e a profissionalização da primeira atividade fora comentada por Bilac, em crônica publicada na Gazeta de Notícias do dia dois de agosto de 1903:

\begin{abstract}
Hoje, não há jornal que não esteja aberto à atividade dos moços. O talento já não fica à porta, de chapéu na mão, triste e encolhido, farrapão e vexado, como o mendigo que nem sabe como há de pedir a esmola. A minha geração, se não teve outro mérito, teve este, que não foi pequeno: desbravou o caminho, fez da imprensa literária uma profissão remunerada, impôs o trabalho. Antes de nós, Alencar, Macedo e todos os que traziam a literatura para o jornalismo, eram apenas tolerados: só a política e o comércio tinham consideração e virtude. Hoje, oh! espanto! Já há jornais que pagam versos! (Dimas, 1996: 56).
\end{abstract}

Foi, então, pelo jornalismo que o meio cultural brasileiro se manteve em contato com os grandes centros estrangeiros e os escritores puderam alcançar um maior número de leitores. A atividade na imprensa dava a esses escritores reconhecimento público e prestígio intelectual e político. Reconhecendo no jornalismo uma nova grande força que absorveu a atividade intelectual na passagem do Império para a República, invadindo territórios até então intocados, Sevcenko (1983: 101) aborda o outro lado da moeda:

\begin{abstract}
O jornalismo, impondo uma vigorosa padronização à linguagem e empregando praticamente todos os homens de letras nas suas redações, acabou necessariamente exercendo um efeito geral negativo sobre a criação artística. Tendendo ao sufocamento da originalidade dos autores e contribuindo em definitivo para o processo de banalização da linguagem literária, suas baixas remunerações exigiam ainda uma facúndia e prolixidade tal dos escritores, que impediam qualquer preocupação com o apuro da expressão ou do estilo.
\end{abstract}

A crônica foi, então, a forma oportuna de passagem entre os dois territórios, subscrevendo um novo estilo, contaminado pelo enquadramento fragmentário da diagramação das folhas, pela pressão dos horários e pela velocidade da própria movimentação das rotativas. As novas técnicas de impressão e edição barateiam

Estudos em Jornalismo e Mídia - Ano VI - n. 1 pp. 11 - 22 jan./jun. 2009 
a imprensa e a linguagem mais simples da crônica facilita o seu consumo cotidiano pelas camadas alfabetizadas, em que pesem serem minoritárias no Brasil: "Cria-se assim uma "opinião pública" urbana, sequiosa do juízo e da orientação dos homens de letras que preenchiam as redações" (Sevcenko, 1983: 94).

Todas essas mudanças são resultado da velocidade com que a tecnologia avançava no tempo e foram sentidas de forma contundente - e concomitante com as transformações econômicas e sociais - na produção literária. Do lento livro passa-se à imprensa veloz. Do livro eterno passa-se à transitoriedade da folha que morre. Do livro de poucos leitores passa-se ao grande público. Ou lembrando Machado de Assis, num texto publicado em $O$ Espelho de 1859, a palavra "falada na tribuna é prodigiosa, é criadora, mas é o monólogo; escrita no livro, é ainda criadora, é ainda prodigiosa, mas ainda é o monólogo; esculpida no jornal, é prodigiosa e criadora, mas não é o monólogo, é a discussão" (Coutinho, 1959: vol. 3).

\section{Referências}

ARMAÑANZAS, Emy; NOCI, Javier Diaz. Periodismo y argumentación: géneros de opinión. Bilbao: Universidad del País Vasco, 1996.

ARRIGUCCI JR., Davi. Enigma e comentário: ensaios sobre literatura e experiência. São Paulo: Companhia das Letras, 1987.

ASSIS, Machado de. Memórias póstumas de Brás Cubas. $3^{a}$ ed. São Paulo: FTD, 1992.

Literatura brasileira - Instinto de nacionalidade. In: Crítica literária. Rio de Janeiro, São Paulo, Porto Alegre: Jackson, 1955.

BORINSKI. Die Antike in Poetik und Kunsttheorie. In: BENJAMIN, Walter. Origem do drama barroco alemão. Tradução, apresentação e notas: Sergio Paulo Rouanet. São Paulo: Brasiliense, 1984.

CANDIDO, Antonio. Literatura e subdesenvolvimento. In: A educação pela noite e outros ensaios. $2^{\mathrm{a}}$ ed. São Paulo: Ática, 1989.

. A crônica: o gênero, sua fixação e suas transformações

no Brasil. São Paulo: Editora da UNICAMP; Rio de Janeiro: Fundação Casa Rui Barbosa, 1992.

COUTINHO, Afrânio (org.). Machado de Assis - Obra Completa. Rio de Janeiro: Aguilar, 1959. vol. 3.

DIMAS, Antônio (org.). Vossa insolência: crônicas / Olavo Bilac. São Paulo: Companhia das Letras, 1996.

FREYRE, Gilberto. Ordem e Progresso. $3^{\text {a }}$ ed. Rio de Janeiro: José Olympio, 1974.

MEYER, Marlyse. Voláteis e versáteis. De variedades e folhetins se faz a chronica. In: CANDIDO, Antonio (et al.). A educação pela noite e outros ensaios. $2^{\text {a }}$ ed. São Paulo: Ática, 1989. pp 93-133.

NEEDELL, Jeffrey D. Belle époque tropical: sociedade e cultura de elite no 
Rio de Janeiro na virada do século. Tradução: Celso Nogueira. São Paulo: Companhia das Letras, 1993.

SCHWARZ, Roberto. Ao vencedor as batatas. $4^{\mathrm{a}}$ ed. São Paulo: Duas Cidades, 1992 .

SCHWARZ, Roberto. Um mestre na periferia do capitalismo: Machado de Assis. São Paulo: Duas Cidades, 1990.

SEVCENKO, Nicolau. Literatura como missão: tensões sociais e criação cultural na Primeira República. $3^{a}$ ed. São Paulo: Brasiliense, 1983.

SODRÉ, Nelson Werneck. História da Imprensa no Brasil. $2^{\mathrm{a}}$ Ed. Rio de Janeiro: Graal, 1977.

Recebido em 18 de fevereiro de 2009. Aprovado em 06 de abril de 2009. 